\title{
O AVESSO DO CARÁTER PROCEDIMENTAL DA CONSTITUIÇÃO: ATIVISMO JUDICIAL, "NOVO" CPC E STF
}

\author{
Henrique Garbellini Carnio* \\ Joaquim Eduardo Pereira**
}

SUMÁRIO: Introdução; 1.1 O Caráter Procedimental da Constituição; 2 A Crise Deflagrada em Dois Exemplos de Casos Julgados pelo STF; 2.1 Mutação Constitucional; 2.2 Controle Jurisdicional do Processo Legislativo e Acirramento da Tensão (que-não-se-resolve); 3 A Crise Refletida no "Novo" CPC; Referências.

RESUMO: O presente artigo pretende discutir uma concepção do caráter procedimental da Constituição que parece não estar sendo adequadamente levado em consideração em nosso país, a saber, como avesso ao ativismo judicial e as formas dissimuladoras de governabilidade reveladas em conflitos relativos aos poderes institucionais brasileiros. Nesse trilho, o texto ao tempo que procura expor um cenário deflagrado de crise dos rumos que a relação entre a teoria e a prática jurídica têm tomado em nosso país, apresenta criticamente dois exemplos que procuram elucidar o objeto desta crise; o primeiro trata de uma situação paradoxal em duas decisões do STF e o segundo sobre o novo CPC e a atividade jurisdicional. A Constituição não pode ser utilizada para bloquear discussões fundamentais nem para sustentar interpretações ilegais, refletir sobre isso em tempos cínicos é o que almeja de forma e em tom introdutório este texto.

PALAVRAS-CHAVE: Caráter procedimental da Constituição; Exceção; Novo CPC; Poderes institucionais; STF.

\section{THE OPPOSITE OF THE PROCEDURE TRAIT OF THE CONSTITUTION: JURIDICAL ACTIVISM, THE NEW CIVIL CODE AND STF}

ABSTRACT: A procedure trait of the Brazilian Constitution which does not seem to be adequately taken into consideration in Brazil is discussed. Or rather, the opposition against juridical activism and the pretended forms of governability in

Doutor e Mestre em filosofia do direito e do estado pela Pontifícia Universidade Católica (PUCSP), Pós-doutor em Filosofia pelo Instituto de Filosofia e Ciências Humanas da Universidade Estadual de Campinas (UNICAMP); Docente permanente do Programa de Pós-Graduação mestrado e doutorado em Direito da Faculdade Autônoma de Direito (FADISP), São Paulo (SP), Brasil. E-mail: henriquegarbellini@yahoo.com.br

* Mestre em direitos humanos pela Pontifícia Universidade Católica (PUCSP); Docente da graduação em direito da Faculdade Autônoma de Direito (FADISP), São Paulo (SP), Brasil. 
conflicts related to Brazilian institutional authorities. The paper describes a crisis between juridical theory and practice in Brazil through the critical explanation of two examples that elucidate the object of the crisis. The first example deals with the paradoxical situation of two decisions by the STF and the second comprises the new $\mathrm{CC}$ and jurisdictional activity. The Constitution may not be employed to limit basic discussions or to sustain illegal interpretations. The text is a reflection on the above in cynical times.

KEY WORDS: Constitution's procedure traits; New CPC; STF; Exception; Institutional powers.

\section{EL ANVERSO DEL CARÁCTER PROCEDIMENTAL DE LA CONSTITUCIÓN: ACTIVISMO JUDICIAL, "NUEVO" CPF Y STF}

RESUMEN: Ese artículo pretende discutir una concepción del carácter procedimental de la Constitución que parece no estar siendo adecuadamente llevado en consideración en nuestro país, a saber, como anverso al activismo judicial y las formas disimuladoras de gobernabilidad reveladas en conflictos relativos a los poderes institucionales brasileños. En esa perspectiva, el texto busca exponer un escenario deflagrado de crisis de los rumbos que la relación entre la teoría y la práctica jurídica tienen seguido en nuestro país, presenta críticamente dos ejemplos que buscan elucidar el objeto de esa crisis; el primer trata de la situación paradoxal en dos decisiones del STF y el segundo sobre el nuevo CPC y la actividad jurisdiccional. La Constitución no puede ser utilizada para bloquear discusiones fundamentales ni tampoco para sostener interpretaciones ilegales, reflexionar sobre eso en tiempos cínicos es lo que almeja de forma y en tonos introductorio este texto.

PALABRAS-CLAVE: Carácter procedimental de la Constitución; nuevo CPC, STF, excepción; poderes institucionales.

\section{INTRODUÇÃO}

Existe uma grande expectativa em relação à entrada em vigor nos próximos dias do Novo Código de Processo Civil. Desde o começo o projeto recebeu inúmeras críticas, houve várias alterações e muito debate dos juristas e interessados em todo o país. Independentemente de fazer um juízo de valor sobre o código em si, ou seja, em relação ao seu conteúdo material e até mesmo sobre a necessidade ou não de um 
novo Código de Processo Civil, nos interessa aqui chamar a atenção para um ponto que passa despercebido nas discussões de cunho eminentemente processualista. Trata-se de tentar demonstrar como a compreensão que o imaginário jurídico faz do processo pode revelar atraso de nossa compreensão para temas mais essenciais.

A proposta aqui pretendida, então, é a de trazer para a discussão uma concepção do caráter procedimental da Constituição que parece não ser levado em consideração e que é essencial, pois diz respeito à própria compreensão do que seja uma Constituição comprometida com um Estado Democrático de Direito e apta a ser efetivada no contexto dessa importante modificação legislativa, uma vez que ela propicia, de modo fundamental, uma investigação crítica, de caráter epistemológico, sobre os rumos que nosso país tem tomado na articulação da relação - intrínseca - entre teoria e prática jurídica. A nosso ver estes rumos são obscuros e refletem os veios de uma extremada e bem delimitada concentração de poder na dimensão e utilização dos poderes institucionais brasileiros que deflagra uma crise, não explicitamente revelada, da governabilidade e o modo peculiar de uma dissimulação que aposta e se baseia, por exemplo, em conceitos como os de democracia e Estado Democrático de Direito, mas, paradoxalmente, faz destes conceitos o lugar velado da velha forma da insígnia do poder soberano que apesar de atuar sob novas roupagens, mantem-se íntegro naquilo que representa sua forma constitutiva, a exceção.

Para empreender essa tarefa, de forma inicial e propositiva, primeiramente vamos explicitar o que compreendemos por caráter procedimental da Constituição e o quanto tal compreensão é imprescindível para se desvincular de propostas ainda vinculadas a paradigmas que não são compatíveis com um Estado Democrático de Direito, mesmo que se suponham superadoras de tais paradigmas. Em seguida passaremos à análise de alguns julgados do Supremo Tribunal Federal em que poderemos mostrar a dificuldade que temos de, realmente, superar velhos paradigmas ao confrontar algumas (corretas) críticas às decisões em apreço com a questão que envolve a apreciação, mesmo que reticente, de um novo Código de Processo Civil.

\subsection{O CARÁTER PROCEDIMENTAL DA CONSTITUIÇÃO}

A Constituição Federal, do modo como a compreendemos hoje, ou seja, com força normativa e como lugar de contato entre o Direito, a Moral e a Política, donde 
assume-se que são diferentes, porém não totalmente separados, é fenômeno recente na história, tendo se desenvolvido nos Estados Unidos com bastante antecedência em relação à Europa, mas que hoje pode ser encarado como uma característica fundamental dos países ocidentais que se pretendem democráticos.

Para se chegar a esta compreensão na dimensão global que assume hoje foram fundamentais as concepções de Hans Kelsen e Carl Schmitt, os quais partem do pressuposto de que as formas de organização vigentes até então se baseavam em conceitos e ideias teológicas que foram secularizados. Desenvolvem suas teorias em sentidos contrários, aquele priorizando o formalismo, este priorizando a materialidade da Constituição.

De qualquer modo, ambos valem como dois pólos opostos, como
duas extremidades doutrinárias, sendo assim as duas orientações
que mais se distanciam mutuamente na compreensão do conceito de
Constituição: Kelsen com a teoria normativa, Schmitt, com a teoria
material; Kelsen sustentando, conforme observa Wimmer, que 'algo
vale, quando vale e porque vale' ('Etwas gilt, wenn es gilt und weil
es gilt') e Schmitt, com seu sentido de existencialidade, professando
que 'algo vale, quando existe e porque existe' ('Etwas gilt, wenn es
ist und weil es ist') ${ }^{01}$.

A rigor, enquanto em Kelsen o positivismo jurídico se mostra como satisfeito na noção pressuposta categorial da imputação, da norma estatal e do dever-ser, além do descompromisso com o plano da facticidade causal - compondo um sistema lógico de regras escalonadas hierarquicamente, em um plano ideal de perfeita consistência, coerência e completude -, em Schmitt temos a exceção que constitui e explica o próprio direito, sendo no momento da decisão em que se manifesta a essência do jurídico ${ }^{02}$.

O que nos interessa, preocupados em não extrapolar os limites da investigação, é mostrar que esta polarização pode ser assumida como o pano de fundo para todo o desenvolvimento posterior do constitucionalismo, sendo que as mais variadas propostas não podem se esquivar de reconhecê-la e tomá-la como ponto de partida.

De modo geral podemos considerar que o constitucionalismo, desde então, na sua proposta fundamental de instituir uma ordem política originária capaz

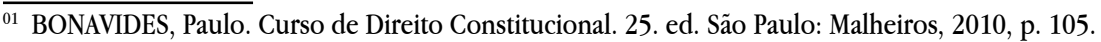

${ }^{02}$ Cf. CARNIO, Henrique Garbellini. Para uma crítica da forma jurídica. Revista de Direito Privado, São Paulo, n. 58, abr. 2014.
} 
de sustentar o convívio social da melhor forma possível, deve ter primeiramente explicitado sua forma de legitimação, da qual deve decorrer a legitimidade de todas as decisões essenciais no tocante à organização político-jurídica de um país, sendo que tal fundamento não pode ser mais, como antes, um ente transcendente ou transcendental como a Razão.

Acontece que em um contexto de guerras, crises econômicas e sociais, em que o Estado Liberal vai perdendo cada vez mais a capacidade de manter a ordem e a integridade da sociedade, surge como resposta o Estado Social, mas que se reveste em muitos países em Estados Ditatoriais e até Totalitários. Porém, nenhuma destas formas de Estado dispensou a Constituição, pelo menos nos discursos justificadores, de modo que as teorias de Kelsen e Schmitt, apesar de contrárias, aquela de cunho formalista que apostava no normativismo, esta assentada em um materialismo que descambou para o decisionismo.

No segundo pós-guerra os países que passaram por governos ditatoriais ou totalitários buscam a redemocratização, o que traz à tona novamente as discussões a respeito da Constituição, as quais assumem novas roupagens, devido às novas contingências, mas o pano de fundo continua o mesmo: saber qual o melhor modo de fundamentar a Constituição e, portanto, como consolidar a democracia, de modo que nem esta nem aquela possam, novamente, ser solapadas por incongruências e interpretações que possam sugerir caminhos outros que não a limitação do Poder, agora não mais só do Estado, mas de qualquer instituição que possua força - bélica, econômica, social, religiosa ou de qualquer outra índole - suficiente para, em seu exercício, colocar em risco outras instituições e, principalmente, qualquer pessoa, esteja esta vinculada a um grupo ou país específico ou não.

Se em um primeiro momento observou-se o prestígio de um modelo social e, mesmo, socialista de Estado, a fórmula do Estado Democrático firma-se a partir de uma revalorização dos clássicos direitos individuais de liberdade, que se entende não poderem jamais ser demasiadamente sacrificados em nome da realização de direitos sociais. O Estado Democrático de Direito, então, representa uma forma de superação dialética da antítese entre os modelos liberal e social ou socialista de Estado $^{03}$.

Tal empreendimento é tão complexo que ao explicitar os problemas fundamentais a serem enfrentados pelo constitucionalismo Lenio Streck afirma que:

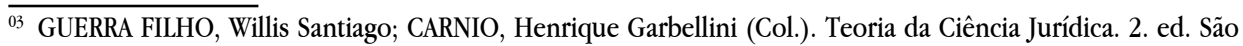
Paulo: Saraiva, 2009, p. 185-186. 
sem pretender reduzir a discussão a uma polarização a duas posições ou teses, mas correndo (e assumindo) o risco de assim fazer, é possível assentar o problema a partir de dois eixos analíticos: o procedimentalismo e o substancialismo. Muito embora procedimentalistas e substancialistas reconheçam no Poder Judiciário (e, em especial, da justiça constitucional) uma função estratégica nas Constituições do pós-guerra, a corrente procedimentalista, capitaneada por autores como Habermas, Garapon e Ely, apresenta consideráveis divergências com a corrente substancialista, sustentada por autores como Cappelletti, em alguma medida por Dworkin e no Brasil por juristas como Paulo Bonavides, Celso Antônio Bandeira de Mello, Ingo Sarlet, José Adércio Sampaio, Fábio Comparato, entre outros ${ }^{04}$.

Partimos de uma forma de abordagem um pouco diferente para tentar explicitar, apesar da dificuldade, o que entendemos como o caráter procedimental da Constituição. Primeiramente cabe ressaltar que não se confunde o que defendemos com o que acima foi designado como as teorias procedimentalistas, antes de tudo porque não compartilhamos de alguns de seus pressupostos percebidos em algumas de suas vertentes, como a desconsideração de conteúdos materiais na Constituição, nos quais reconhecemos principalmente os direitos fundamentais, e também não compartilhamos da busca de condições ideais de diálogo entre os participantes, mas sim de que estes já partem de condições que limitam as compreensões que têm de si mesmos.

Ademais, como entendemos ser o cerne de uma proposta capaz de se sustentar e superar os problemas da identificação com qualquer um dos lados, afigura-nos mais promissor reconhecer além das diferenças, as similitudes de tais propostas. Isto porque estas, apesar de contrárias - ou talvez justamente por isso - são também complementares, uma vez que os fundamentos de uma residem, basicamente, na negação da outra, o que não impede se combinarem no âmbito da pragmática.

Então, sem uma intenção demasiada simplista de mesclar paradigmas concorrentes e apostar em sincretismos epistemológicos, reconhecemos que a possibilidade de uma superação dialética não significa apenas uma somatória simples ou a junção do que de melhor há em cada posição. Trata-se, a rigor, de levar em consideração cada uma das posturas, especialmente no que elas têm de importância em relação a direitos fundamentais para, depois, em um processo

${ }^{04}$ STRECK, Lenio Luiz. Hermenêutica jurídica e(m) crise: uma exploração hermenêutica da construção do Direito. 8. ed. Porto Alegre: Livraria do Advogado, 2009, p. 38. 
dialógico e construtivo, levando-se em conta o maior número possível de pontos de vista envolvidos, oferecer respostas que respeitem tanto seu próprio modo de formulação quanto direitos fundamentais que conformam-no materialmente.

Diante da complexidade do mundo (pós)moderno, as soluções melhores só aparecem quando se procura colocar as opiniões divergentes em comunicação, partindo de um consenso em torno da possibilidade de se chegar a um entendimento mútuo. Para isso, contudo, não se pode já partir de ideias preconcebidas, que se deve impor aos outros. O melhor a fazer é deixar que a solução se mostre, pragmaticamente, na situação comunicativa; e de antemão se pode refletir sobre o procedimento a ser adotado, para chegar a soluções que harmonizem os interesses individuais e coletivos, com base em um princípio de proporcionalidade ${ }^{05}$.

Para que fique claro em que medida temos pensado o sentido constitutivo da proporcionalidade e o direito que aqui se lança, cabe retomarmos o último diálogo de Platão, "As Leis", no qual este recomenda dois conceitos básicos significativos para o pensamento jurídico, a saber, o de constituição mista e o de igualdade proporcional. Se o poder excessivo produz o absolutismo tirânico e a liberdade demasiada a demagogia, então a fórmula ideal está no respeito à liberdade com autoridade na "justa medida". A igualdade não é baseada em um igualitarismo abstrato, mas distribuída de forma proporcional. A "justa medida" assume, nesse momento, posição predominante no pensamento de Platão, tão predominante que ela não deixa de se revelar, expressamente, sua fundamentação de caráter tipicamente teológico, a de que a medida de todas as coisas é Deus ${ }^{06}$.

A lógica de como o direito tem lidado com a questão da aplicação da proporcionalidade encontra sua guarida nas propostas procedimentais das teorias das decisões judiciais, como já observado, mas, a nosso ver, reside também no modo

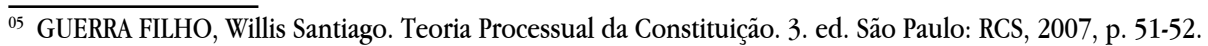

${ }^{06}$ Cf. REALE, Giovanni. História da filosofia: filosofia pagã antiga, v. 1. São Paulo: Paulus, 2003, p. 158-159. Nesse contexto, vale lembrar o texto Deus e Estado de Kelsen. Ele inicia fazendo a instigante referência de como o problema religioso e o problema social apresentam um notável paralelismo. A vivência social se manifesta na consciência do indivíduo como vinculada a outros seres, o que, em desenvolvimento gerará a representação de uma subordinação e dependência do próprio eu, o que corresponde necessariamente à representação complementar de uma autoridade que institui o engendramento social. Nesse sentido, em termos sociais Deus e Estado são os atores principais da representação social. Se lhe retiram as máscaras, tais representações - religiosa ou social - da esfera política o que acontece é que deixa de ser Deus aquele que recompensa e castiga e deixa de ser o Estado aquele que condena e faz a guerra: "são homens que exercem violência sobre outros homens, é o senhor x quem triunfa sobre o senhor e, ou uma besta que aplaca seu apetite sanguinário revivido". Metodologicamente, retirar as máscaras é o ponto em que se apoia a biologia e a psicologia orientadas pelas ciências naturais, porém, tal enfoque não leva em conta nem religião, nem nação, nem estado. Cf. KELSEN, Hans. Dios y estado. In: El otro Kelsen. Óscar Correas (Org.). Trad. Jean Hennequin, México: Universidad Nacional Autónoma de México, 1989, p. 243-244. 
em que se vem pensando a imputação jurídica. O retorno à sua compreensão é fundamental para encarar o desafio da tratativa da proporcionalidade.

Este pressuposto epistemológico que assumimos nos permite, ao abordar as questões fundamentais que tomam conta do imaginário político-jurídico hodiernamente, não partir de um modo de proceder previamente estipulado, o que a despeito da "segurança jurídica" que se pretende assim garantir, tem como consequência não apenas limitar as respostas que podem ser oferecidas, mas mais precisamente a compreender de forma mais autêntica quais são os problemas fundamentais a serem solucionados.

Pretendemos, a partir de agora, delimitando o objeto de exploração deste artigo, mostrar como que posturas equivocadas podem, tanto quanto posturas que permitem explicitar os equívocos e apontar incongruências e ilegitimidades, sequestrar as discussões e mantê-las em âmbitos senão de falsos problemas, de questões secundárias em relação a outras mais essenciais e que são, quando levadas a discussão, rechaçadas de plano e veementemente por posturas que se pretendem críticas, mas podem, apesar de mais bem estruturadas e coerentes, compartilhar de um paradigma ou de pressupostos que as impedem de abrir mão do formalismo ou da segurança jurídica, quer dizer, do Estado de Direito, não de modo a fazê-lo sucumbir frente ao Estado Democrático ou Social, e vice-versa, de modo que se mantêm as discussões em um plano em que não é possível uma superação dialética e, portanto, legítima, ou seja, não apenas correta ou eficiente.

\section{A CRISE DEFLAGRADA EM DOIS EXEMPLOS DE CASOS JULGADOS PELO STF}

\subsection{MUTAÇÃO CONSTITUCIONAL}

O primeiro caso, que passamos agora a analisar, trata-se da Reclamação 4.335/ AC, em que o Supremo Tribunal Federal se debruçou sobre a questão do papel que o Senado desempenha em casos de controle difuso de constitucionalidade. Estava em discussão o artigo 52, X CF, que diz que cabe ao Senado Federal suspender a execução, no todo ou em parte, de lei declarada inconstitucional pelo STF em sede de controle difuso. 
Ocorre que o Min. Relator Gilmar Mendes disse em seu voto que estarse-ia face a um caso de mutação constitucional, uma vez que a jurisprudência do STF e muitas reformas constitucionais ${ }^{07}$ apontam no sentido de que estaríamos caminhando no sentido de uma concentração do controle de constitucionalidade no Brasil. Portanto, a remessa da decisão do STF para o Senado deveria ter o condão de, apenas, dar publicidade à decisão, não cabendo ao último decidir pela retirada ou não da lei declarada inconstitucional do ordenamento, ou seja, com efeito vinculante erga omnes.

O ministro Eros Grau acompanhou o entendimento acima, porém, reconheceu expressamente em seu voto tratar-se, no caso, de uma alteração do próprio texto constitucional, que a partir de então seria: "compete privativamente ao Senado Federal dar publicidade à suspensão da execução, operada pelo Supremo Tribunal Federal, de lei declarada inconstitucional, no todo ou em parte, por decisão definitiva do Supremo".

Parcela modesta da comunidade jurídica ${ }^{08}$ se indignou e veio a público expressar o quão prejudicial e perigoso seria, para o aperfeiçoamento do recente e ainda instável processo de redemocratização do Brasil, vingar esta tese exarada pelos ministros Gilmar Mendes e Eros Grau.

Um dos principais argumentos levantados contra esta interpretação foi que não se trataria de mutação constitucional, mas sim de alteração formal da Constituição, pois aquela não ocorre como um ato deliberado, mas sim como modificações que acontecem naturalmente na interpretação devido às mudanças por que passa a sociedade. Deve-se destacar também que a mutação constitucional é uma mudança da norma, enquanto que na alteração formal o que se muda é o próprio texto da Constituição, partindo-se da diferença entre texto e norma de Friedrich Müller ${ }^{09}$.

Além do fato de uma alteração formal da Constituição não poder ser feita pelo STF, mas sim através das vias legislativas, posto que aquele não tem legitimidade

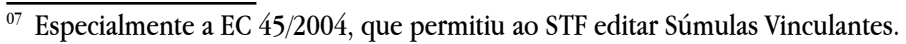

${ }_{08}$ Disponível em: http://www.mundojuridico.adv.br/cgi-bin/upload/texto1300.pdf; http://www12.senado.gov. br/publicacoes/estudos-legislativos/tipos-de-estudos/outras-publicacoes/volume-iii-constituicao-de-1988-o -brasil-20-anos-depois.-a-consolidacao-das-instituicoes/jurisdicao-constitucional-o-senado-federal-e-o-controle-concreto-de-constitucionalidade-de-leis-e-de-atos-normativos-separacao-de-poderes-poder-legislativo-e-interpretacao-da-cf-52-x; http://www.abdconst.com.br/revista3/franca.pdf

${ }^{09}$ Sobre conceito de norma elaborado por Müller, ver: O novo paradigma do direito. São Paulo: Revista dos Tribunais, 2007, n. 43, p. 119; n. 7, p. 148. Teoria Estruturante do Direito. São Paulo: Revista dos Tribunais, 2008, I, p. 80. 
popular, já que seus integrantes não são eleitos pelo povo, causa ainda maior espanto o fato de que a tese esboçada pelos ministros vai no sentido de aumentar o poder do STF em relação ao Poder Legislativo, no caso representado pelo Senado, no que se colocaria em risco o equilíbrio dos poderes e, portanto, a democracia.

A pretensa tendência de concentração no que diz respeito ao controle de constitucionalidade nada mais significa que abolir diferenças significativas entre $o$ controle difuso e o concentrado, o que teria como consequência uma concentração de poder no STF, deixando este de se portar como guardião da Constituição para se estabelecer como proprietário de seu sentido. O que se mostra na contramão da própria ideia fundamental do constitucionalismo, a saber, limitação do poder.

O papel do Senado descrito no artigo 52, X da CF, é de fundamental importância para a legitimidade do jogo democrático, posto que o nosso controle difuso de constitucionalidade, diferentemente do estadunidense, que o inspirou, não possuía em sua origem um mecanismo de transcender a eficácia da declaração de inconstitucionalidade do caso concreto para o plano abstrato, que naquele país se dá pelo instituto do stare decisis.

O Senado Federal foi escolhido como o órgão, com representação popular, para poder cumprir esta função. E o que se deve levar em consideração é que temos um sistema misto de controle de constitucionalidade, enquanto que nos EUA não há o controle abstrato. A supressão do papel do Senado geraria grave descontrole no equilíbrio dos Poderes, além de praticamente minar o controle difuso de constitucionalidade, o que, aliás, parece ser defendido por alguns juristas, dentre eles ministros do STF, no que a pretensa mutação constitucional, é uma alteração formal da Constituição por via inapropriada e que fere fundamentalmente seus princípios, pois propicia a concentração desproporcional de poder, quando deveria servir precipuamente para limitá-lo. O STF estaria, em realidade, deixando de aplicar (corretamente) a Constituição Federal, a pretexto de expressar seu sentido.

Apesar de ter-se explicitado nos estudos acima resumidos os perigos iminentes para a nossa democracia, a tese exarada inicialmente pelos ministros Gilmar Mendes e Eros Grau veio a ser confirmada quando o julgamento foi concluído após voto-vista do ministro Teori Zavascki, cujo entendimento foi seguido pelos ministros Luís Roberto Barroso, Rosa Weber e Celso de Mello, no sentido de que "é inegável que, atualmente, a força expansiva das decisões do STF, mesmo quando tomadas em casos concretos, não decorre apenas e tão somente da resolução do 
Senado, nas hipóteses do artigo 52, inciso X, da Constituição" e que este fenômeno "está se universalizando por força de todo um conjunto normativo constitucional e infraconstitucional direcionado a conferir racionalidade e efetividade às decisões dos Tribunais Superiores e especialmente à Suprema Corte".

O que nos interessa destacar então, para o escopo do presente estudo, são os seguintes pontos: a) fato de que o próprio STF diz haver em nosso ordenamento jurídico uma tendência à concentração do controle de constitucionalidade, devendo prevalecer os efeitos e consequências do controle concentrado, inclusive quando se tratar de controle difuso; b) tal tese foi brilhantemente combatida por exímios juristas, que demonstraram tratar-se de tese que permitiria, na verdade, equiparar o controle difuso de constitucionalidade ao concentrado, sendo, portanto, contrária à Constituição e à democracia, concentrando desproporcionalmente no STF poderes que poderiam transformá-lo em um super Poder, acima da Constituição Federal, o que esvaziaria o sentido desta; c) apesar da seriedade do tema e sobriedade e excelência com que tal tese foi desconstruída, expondo-se suas incongruências e ilegitimidade, ela veio a se confirmar no julgamento final do caso em questão, sendo que não se viu, por isso, insurreição por parte da comunidade jurídica em geral ${ }^{10}$; d) acirramento da tensão entre o STF e o Poder Legislativo, que desenvolveremos melhor no próximo tópico, de modo que esta tensão envereda-se para soluções contrapostas, porém ambas incorretas.

Passaremos, a seguir, a analisar uma decisão em que poderemos destacar a mesma tendência do STF em exceder seus poderes, em nome de um ilegítimo ativismo judicial, tomando decisões estritamente políticas, impassíveis de serem justificadas à luz da Constituição Federal e no âmbito de um Estado Democrático de Direito. Logo em seguida trazemos outra decisão, para um caso análogo em que, porém, o STF dá uma decisão em sentido contrário e depois até modifica a primeira que tinha se dado liminarmente. Apesar disso, o STF sinaliza no sentido de que não mudou fundamentalmente a propensão ao ativismo judicial. Assim poderemos ampliar o debate, mostrando como que a flagrante ilegitimidade do STF se apropriar da Constituição não se verifica quando esta apropriação se pretende expandida, porém não além dos limites do Direito, ou melhor, da comunidade jurídica, mesmo se

\footnotetext{
${ }^{10}$ Apesar de se reconhecer que vem aumentando consideravelmente o número de juristas e até outros setores da sociedade que se propõem a combater o Ativismo Judicial, especialmente no âmbito do STF e demais cortes superiores, podemos constatar que se trata de parcela quantitativamente diminuta, se comparada aos que defendem tal atuação e, principalmente, os que sequer reconhecem efetivamente a magnitude desta questão, tratando a discussão como não essencial ou a partir de um pragmaticismo consolador.
} 
tratando de setores mais críticos. Enquanto isso aumenta a tensão com o Legislativo, o qual começa a tomar medidas que acirram a tensão de modo a solidificar ainda mais uma polaridade infrutífera para a democracia e que a despeito de proteger a Constituição lados opostos tendem a esvaziar seu significado, desconsiderando seu caráter procedimental como defendemos.

\subsection{CONTROLE JURISDICIONAL DO PROCESSO LEGISLATIVO E ACIRRAMENTO DA TENSÃO (QUE-NÃO-SE-RESOLVE)}

Vamos tecer algumas considerações sobre a possibilidade de haver controle prévio de constitucionalidade feito pelo judiciário, sendo que a intenção se projeta no sentido de tentar compreender a tensão gerada entre o Judiciário e o Legislativo em relação aos limites de suas atividades e o respeito à Constituição, no sentido de nos posicionarmos quanto à possibilidade ou não de tal controle. Buscaremos explicitar, portanto, a incompreensão do problema, o que não é levado em consideração e acaba por condicionar respostas ilegítimas.

Primeiramente trazemos à baila outra decisão, em sede de liminar, do ministro Gilmar Mendes, que também compartilha dos mesmos pressupostos que embasaram o posicionamento na questão do artigo 52, X CF, qual seja a aposta no ativismo judicial como forma de concretizar a Constituição.

Trata-se do mandado de segurança preventivo 32033 DF, impetrado pelo Senador Rodrigo Sobral Rollemberg, em que se aduz a violação do devido processo legislativo quanto à tramitação do PL $\mathrm{n}^{0}$ 4.470/2012, o qual estabeleceria que a migração partidária que ocorrer durante a legislatura não importará na transferência dos recursos do fundo partidário e do horário de propaganda eleitoral no rádio e na televisão.

O STF já consolidou jurisprudência no sentido de ser cabível mandado de segurança para controle prévio de constitucionalidade de atos legislativos, mas em situações especiais, buscando, no seu entender, não romper com o equilíbrio de poder, sendo possível, então, não obstante o seu caráter político,

sempre que os corpos legislativos ultrapassem os limites delineados pela Constituição ou exerçam as suas atribuições institucionais com ofensa a direitos públicos subjetivos impregnados de qualificação constitucional e titularizados, ou não, por membros do Congresso Nacional" (MS 24.849, Pleno, Rel. Celso de Mello, DJ 29.9.2006). O 
Tribunal reconhece, ainda, a legitimidade ativa dos parlamentares para provocar esse controle por meio da impetração do mandado de segurança (MS 24.356/DF, Rel. Carlos Velloso, Pleno, DJ 12.09.2003). É também firme o posicionamento desta Corte no sentido do cabimento de mandado de segurança para "coibir atos praticados no processo de aprovação de leis e emendas constitucionais que não se compatibilizam com o processo legislativo constitucional" (MS 24.642, Rel. Min. Carlos Velloso, DJ de 18.6.2004; MS 20.452/DF, Rel. Min. Aldir Passarinho, RTJ, 116 (1)/47; MS 21.642/DF, Rel. Min. Celso de Mello, RDA, 191/200; MS 24.645/DF, Rel. Min. Celso de Mello, DJ de 15.9.2003; MS 24.593/DF, Rel. Min. Maurício Corrêa, DJ de 8.8.2003; MS 24.576/DF, Rel. Min. Ellen Gracie, DJ de 12.9.2003; MS 24.356/DF, Rel. Min. Carlos Velloso, DJ de 12.9.2003.)

\section{Partindo deste pressuposto, o ministro passa a analisar o caso concreto} e decide por conceder a liminar, pois entende que há risco para o equilíbrio de forças e para a democracia, fundamentando seu voto no sentido de que o STF já havia se manifestado sobre o assunto em questão no controle abstrato ${ }^{11}$, situação em que decidiu contrariamente ao conteúdo do projeto de lei objeto do mandado de segurança. Assim, não poderia o Legislativo logo em seguida, como fez,

\footnotetext{
${ }^{11}$ Verbis: "O Supremo Tribunal afirmou que a fidelidade partidária decorria do sistema eleitoral adotado, bem como de outras regras e princípios constitucionais (confiram-se os Mandados de Segurança 26.602, 26.603 e 26.604, de relatoria dos ministros Eros Grau, Celso de Mello e Cármen Lúcia, respectivamente). No julgamento dos referidos mandados de segurança, salientei que a fidelidade partidária condicionava o processo democrático, ao impor normas de preservação dos vínculos políticos e ideológicos entre eleitores, eleitos e partidos. Nesse sentido, o 'transfuguismo' partidário excessivo que se estava a vivenciar contaminava todo o processo democrático, gerando repercussões negativas sobre o funcionamento parlamentar dos partidos. Ao assentar a imperiosidade da fidelidade partidária, a Corte delegou ao Tribunal Superior Eleitoral a edição de Resolução que regulamentasse todos os aspectos decorrentes de sua decisão. Verifique-se trecho da ementa do julgado do MS 26.602, Rel. Min. Eros Grau: '[...] O abandono de legenda enseja a extinção do mandato do parlamentar, ressalvadas situações específicas, tais como mudanças na ideologia do partido ou perseguições políticas, a serem definidas e apreciadas caso a caso pelo Tribunal Superior Eleitoral'. A proibição do 'trocatroca' partidário não representou, por óbvio, a asfixia da liberdade de criação de partidos políticos, garantida pelo art. 17 da Constituição Federal, tampouco a vedação do acesso de novos partidos aos recursos do fundo partidário e ao tempo de propaganda eleitoral no rádio e na televisão, in verbis: Art. 17. É livre a criação, fusão, incorporação e extinção de partidos políticos, resguardados a soberania nacional, o regime democrático, o pluripartidarismo, os direitos fundamentais da pessoa humana e observados os seguintes preceitos: $[\ldots] \S 3^{\circ}$ Os partidos políticos têm direito a recursos do fundo partidário e acesso gratuito ao rádio e à televisão, na forma da lei. Justamente nesse contexto, o STF, ao interpretar os dispositivos transcritos, em Sessão Plenária realizada em 29.6.2012, julgou a ADI 4.430, de relatoria do Ministro Dias Toffoli, e concedeu interpretação conforme a Constituição ao inciso II do $\S 2^{\circ}$ do art. 47 da Lei 9.504/97, para assegurar aos partidos novos, criados após a realização das últimas eleições gerais para a Câmara dos Deputados, o direito de acesso proporcional aos dois terços do tempo destinado à propaganda eleitoral gratuita no rádio e na televisão, considerada a representação dos deputados federais que migrarem diretamente dos partidos pelos quais foram eleitos para a nova legenda no momento de sua criação. Essa interpretação foi observada pelo sistema político nas últimas eleições municipais e, portanto, abarcou os atores políticos aos quais foi aplicada até o momento. O PLC 14/2013 perece afrontar diretamente a interpretação constitucional veiculada pelo Supremo Tribunal Federal no julgamento da ADI 4.430, Rel. Min. Dias Toffoli, a qual resultou de gradual evolução da jurisprudência da Corte, conforme demonstrado. A aprovação do projeto de lei em exame significará, assim, o tratamento desigual de parlamentares e partidos políticos em uma mesma legislatura. Essa interferência seria ofensiva à lealdade da concorrência democrática, afigurando-se casuística e direcionada a atores políticos específicos".
} 
propor projeto de lei que versa em sentido contrário ao que está consolidado na jurisprudência do Supremo.

Trata-se, evidentemente, como no primeiro caso, de decisão que toca na questão delicada dos limites entre a atuação do STF e do Poder Legislativo. E, mais uma vez, parece que o primeiro extrapolou e invadiu a esfera estritamente política, ou seja, decidiu sobre assunto que deveria ser tratado por uma instância com legitimação popular para tanto, para dizer o mínimo.

Virgílio Afonso da Silva teceu críticas veementes a esta liminar concedida, frisando que o ministro agiu de forma equivocada e que

é algo que parece não ter paralelo na história do STF e na experiência internacional. Ao bloquear o debate sobre as novas regras partidárias, Gilmar Mendes simplesmente decidiu que o Senado não poderia deliberar sobre um projeto de lei porque ele, Gilmar Mendes, não concorda com o teor do projeto. Em termos muito simples, foi isso o que aconteceu. Embora em sua decisão ele procure mostrar que o STF tem o dever de zelar pelo "devido processo legislativo", sua decisão não tem nada a ver com essa questão. Os precedentes do STF e as obras de autores brasileiros e estrangeiros que o ministro cita não têm relação com o que ele de fato decidiu. Sua decisão foi, na verdade, sobre a questão de fundo, não sobre o procedimento. Gilmar Mendes não conseguiu apontar absolutamente nenhum problema procedimental, nenhum desrespeito ao processo legislativo por parte do Senado. O máximo que ele conseguiu foi afirmar que o processo teria sido muito rápido e aparentemente casuístico. Mas, desde que respeitadas as regras do processo legislativo, o quão rápido um projeto é analisado é uma questão política, não jurídica. Não cabe ao STF ditar o ritmo do processo legislativo ${ }^{12}$.

$\mathrm{O}$ autor citado ainda reconheceu que não há dúvida de que a última palavra em questões constitucionais deve ser da Corte Constitucional, porém isto não quer dizer que esta pode dizer o que quiser, não é proprietária do sentido da Constituição. Portanto, no caso houve claramente abuso na interpretação exarada pelo ministro. E, além disso, acena para o fato de que a Corte ter como pacífica a possibilidade de controlar a constitucionalidade do processo legislativo já é, em si, duvidoso ${ }^{13}$.

\footnotetext{
${ }^{12}$ Disponível em: < http://jornalggn.com.br/blog/luisnassif/a-emenda-e-o-supremo-por-virgilio-afonso-da-silva >

13 "Sua decisão apoia-se em uma única e singela ideia, que pode ser resumida pelo argumento 'se o projeto for aprovado, ele será inconstitucional pelas razões a, b e c'. Ora, não existe no Brasil, e em quase nenhum lugar do mundo, controle prévio de constitucionalidade feito pelo Judiciário. Mesmo nos lugares onde há esse controle prévio - como na França - ele jamais ocorre dessa forma. Na França, o Conselho Constitucional pode analisar a constitucionalidade de uma lei antes de ela entrar em vigor, mas nunca impedir o próprio debate. Uma decisão nesse sentido, de impedir o próprio debate, é simplesmente autoritária e sem paralelos na história do STF e de tribunais semelhantes em países democráticos".
} 
Diferentemente do que ocorreu no outro caso, apesar das críticas da comunidade jurídica terem sido em menor quantidade, estas surtiram efeito e, na decisão do plenário, esta liminar foi cassada e o mandado de segurança foi aceito, mas teve o mérito indeferido.

Aconstitucionalidade do citado projeto de leiera duvidosa, mas a interferência do STF, nos moldes da liminar concedida, não se justificava, até mesmo porque no processo legislativo há comissão especializada para apurar a constitucionalidade do mesmo, além de ter que passar pelas duas casas legislativas. É importante ressaltar que as análises da Comissão de Constituição e Justiça vinculada ao Legislativo não vinculam o Judiciário e, portanto, depois de aprovado projeto de lei, esta ainda poderá sempre ter sua constitucionalidade averiguada no STF. Por isso, o fato deste intervir ainda no processo legislativo afeta sobremaneira o equilíbrio de forças em uma democracia.

Também concordamos com as críticas feitas e repugnamos o ativismo judicial, porém nos interessa mais explicitar o outro lado da questão. Pois, se até pouco tempo se justificava uma postura ativista por parte do Judiciário devido à crise de legitimidade e apatia que assolam nosso Legislativo, este se mostrou incomodado, sendo que elaborou a PEC 33/2011, uma proposta de emenda constitucional que tem a seguinte ementa: "Altera a quantidade mínima de votos de membros de tribunais para declaração de inconstitucionalidade de leis; condiciona o efeito vinculante de súmulas aprovadas pelo Supremo Tribunal Federal à aprovação pelo Poder Legislativo e submete ao Congresso Nacional a decisão sobre a inconstitucionalidade de Emendas à Constituição".

Percebe-se que o Legislativo, especialmente nesta proposta de emenda constitucional, acaba por assumir uma postura defensiva em relação ao ativismo judicial praticado pelo STF, tendo uma reação contrária que pode se mostrar tão equivocada quanto a que pretende combater.

Neste caso também houve a proposição de dois mandados de segurança preventivos com pedido de liminar ${ }^{14}$ com o objetivo de obstar a tramitação e a deliberação da respectiva proposta de emenda constitucional. Porém, desta vez o STF negou a liminar, posto que o Ministro Relator Dias Toffoli disse que não restou caracterizado o periculum in mora, ou fundado receio de lesão irreparável, devendo-se aguardar o regular processamento das ações. É importante ressaltar que

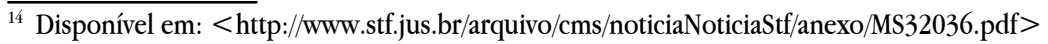


o ministro deixa expressa a possibilidade de reapreciação da matéria em caso de modificação do quadro antes do julgamento definitivo.

Assim como no outro caso, compreendemos que deve-se prezar pela autonomia da discussão na esfera pública com legitimidade para isso, quer dizer, com representação popular, ou seja no Legislativo, o que não impossibilita uma revisão posterior de sua constitucionalidade pela Corte Constitucional, à qual também reconhecemos um papel não de sobreposição, mas de destaque no que diz respeito à efetividade da Constituição e às garantias do Estado Democrático de Direito. Mas o que mais interessa ao estudo não é delimitar os limites para a atuação de cada Poder, mas reconhecer a tensão existente e buscar (re)pensar o modo de compreendê-la, pois o fato desta tensão ser uma decorrência contingencial de um Estado Democrático de Direito com uma Constituição normativa e dirigente significa que esta deve estar acima dos Poderes e, portanto, da própria tensão. Qualquer proposta de se dirimir esta de modo unívoco, como ficou claro que são as tendências nos dois polos, pelo exposto acima, se mostra de saída viciada, a nosso ver, justamente por não reconhecer o caráter procedimental da Constituição como indicado por nós.

\section{A CRISE RELFETIDA NO "NOVO" CPC}

O problema diagnosticado, o ativismo judicial e o acirramento da tensão entre os Poderes Judiciário e Legislativo, têm como pano de fundo a força normativa da Constituição e a necessidade de se efetivá-la em um Estado Democrático de Direito. Tais fenômenos, entretanto, não são um problema em si. Eles suscitam tais problemas devido à complexidade da função que assumem, a de fornecer bases legítimas para o convívio social no mundo pós-moderno.

Partindo-se de uma compreensão equivocada a respeito da Constituição ter-se-á a ocorrência de respostas incorretas, ilegítimas para as questões que permeiam a vida em sociedade, das mais complexas às mais corriqueiras, posto que o constitucionalismo permite superar a separação entre Direito e Política e perceber sua relação de co-pertencimento.

A Constituição não é aplicada somente pelo STF no âmbito do Judiciário, posto que se torna a condição de possibilidade de todo o Direito, para que este se mostre legítimo. Não pode haver, em nenhuma instância, uma decisão ou ato judicial que contrarie a Constituição. Mas, para saber o que a contraria ou não, quais 
são seus limites e como interpretá-la, é preciso se ater, primeiramente, ao que se compreende pelo próprio fenômeno do constitucionalismo.

Temos que buscar um consenso quanto a estas questóes fundamentais, o que não quer dizer que fazendo-o não haverá mais decisões díspares ou incorretas, já que o âmbito em que nos situamos é anterior àquele metodológico. Não se trata, então, de fornecer caminhos através dos quais dever-se-ia interpretar a Constituição, mas problematizar o que, nestes empreendimentos, fica encoberto.

Pois tanto o ativismo judicial quanto a postura que o Legislativo recentemente vem tomando em relação a ele, ambos incorretos, nos parecem compartilhar concepções iguais, ou pelo menos próximas, do que seja a Constituição, de qual seu papel e como aplicá-la. Tanto o Judiciário - pois o ativismo foi explicitado no âmbito do STF devido à sua preponderância, mas é evidenciado em todas as esferas deste Poder - quanto o Legislativo expressam nos respectivos modos de proceder, estarem aplicando a Constituição corretamente.

A doutrina tem um importantíssimo papel ao diagnosticar os excessos e apontá-los, mas a questão não é tão simples. Apesar das críticas trazidas por destacados juristas no que diz respeito à atuação do STF, as quais compreendemos corretas, acreditamos não serem suficientes para resolver problemas fundamentais, os quais podem ser melhor compreendidos e, portanto, solucionados, a partir da compreensão do caráter procedimental da Constituição que já esboçamos.

O que precisa ser enfatizado é que o processo é essencial ao Direito, assim como a força normativa da Constituição e sua concepção substancialista. Esta está atrelada a um modelo de Estado Social, enquanto o processo assume autonomia frente ao direito material em período anterior, quando do predomínio do Estado Liberal e suas tendências ao individualismo e à formalização. Porém, como já indicado, o Estado Democrático de Direito necessita de uma superação dialética destas duas posições, o que quer dizer que não podemos mais acreditar que a tensão possa ser resolvida de uma vez por todas, mas muito menos que pode ser resolvida em uma das direções sem se levar em consideração o lado contrário.

As tentativas de se resolver os conflitos unilateralmente, como mostramos ocorrer na tensão entre o STF e o Legislativo, são comuns nos mais variados âmbitos e nada mais significa que a expressão de posicionamentos que se pretendem fundamentar em uma compreensão da Constituição que não pode ser compartilhada por quem combata tais pontos de vistas. E o mais incongruente é que ambos alegam sempre estarem buscando efetivar a Constituição. 
O que, por fim, mais interessa para a proposta aqui desenvolvida e no sentido da superação dialética defendida é a possibilidade de uma compreensão da Constituição em que esta não possa ser objetificada, ou seja, não possa ser (in)apropriada por quem pressuponha interpretá-la. Isto quer dizer que deve-se reconhecer sua materialidade e força normativa expressas nos direitos fundamentais, e isto significa que qualquer discussão não pode ser arbitrariamente encerrada, mas deve incluir o maior número possível de interessados, sendo a Constituição, especialmente os direitos fundamentais, um ponto de partida comum a ser assumido nas discussões, e não empecilho a estas.

Não há mais que se sustentar a oposição, por exemplo, entre direito material e direito processual. E com isso queremos destacar que o modo como tem sido conduzidas, pela maioria, as discussões acerca do novo código de processo civil deve ser encarado como um sintoma de que não estamos no caminho correto. Pois, apesar de não concebermos o processo como despiciendo, não podemos compartilhar da crença de que um novo diploma, no mesmo molde do antigo, ou seja, no sentido de que parte dos mesmos pressupostos epistemológicos, possa trazer em seu bojo a solução para tantos problemas que assolam nosso judiciário. Pelo menos, não se não for acompanhado de drásticas mudanças institucionais, pois um novo CPC, como está sendo feito, parece que pouco contribuirá para resolver os problemas se não mudarmos as instituições e, consequentemente, as pessoas encarregadas de aplicá-lo.

Das inúmeras críticas ao novo CPC nos interessa as que vislumbram um caráter antidemocrático do projeto, devido a apostas no protagonismo dos juízes e, especialmente, das Cortes Superiores e críticas que vão no sentido de que os problemas da justiça brasileira hoje não podem ser resolvidos por um novo processo civil se não forem resolvidas, antes, as grandes questões administrativas, sendo que falta ao Judiciário como um todo conhecimentos de gestão ${ }^{15}$.

Um exemplo bem adequado nesse sentido foi o fato das entidades de magistrados terem encaminhado à presidente Dilma Rousseff ofícios solicitando

\footnotetext{
${ }^{15}$ Este é o caso, por exemplo, de críticas feitas em um manifesto da $\mathrm{OAB} / \mathrm{SP}$, que além de vislumbrarem um caráter autoritário ao expandir o poder dos magistrados, se destaca que: "Antes de se pensar em um novo diploma processual, devemos nos ocupar, no mínimo, com sete problemas que emperram nosso Judiciário e que nada têm a ver com os defeitos do CPC.

${ }^{1}$ Ausência da vontade política para criar um Judiciário eficiente;

${ }^{2}$. Falta de investimento de recursos orçamentários para o aparelhamento da Justiça;

3. Falta de informatização completa dos órgãos jurisdicionais e administrativos do PJ;

4. Falta de capacitação, motivação e remuneração do pessoal da Justiça;

5. Número relativamente baixo de juízes;

${ }^{6}$ Falta de capacitação específica dos nossos magistrados para administrar cartórios e secretarias;

7. Ausência de padronização da rotina administrativo-cartorária". Disponível em: <http://www.migalhas.com.br/ Quentes/17,MI120563,61044-OABSP+critica + novo+ projeto+do+CPC>.
} 
vetos a dispositivos do Novo Código de Processo Civil, estando entre as principais preocupações dos juízes a fundamentação das decisões judiciais.

No documento enviado à presidente da República, as associações pediram o veto aos artigos 12, 153 e 942, além dos parágrafos $1^{\circ}, 2^{\circ}$ e $3^{\circ}$ do artigo 489 e do parágrafo $1^{\circ}$ do artigo 927 . Vale lembrar que o texto foi assinado pela Associação dos Juízes Federais do Brasil (Ajufe), Associação dos Magistrados Brasileiros (AMB) e Associação Nacional dos Magistrados da Justiça do Trabalho (Anamatra).

De forma pontual, os magistrados deveriam lutar para melhora da estrutura de trabalho para magistrados e para tribunais e não em buscar vetos que implicam diretamente em diminuição de garantias, já asseguradas pela própria Constituição em seu art. 93, IX.

Entretanto, depois de já aprovado o novo CPC, antes mesmo de entrar em vigor este já sofreu uma alteração significativa. O projeto de lei n ${ }^{0} 168$ de 2015 da Câmara dos Deputados foi aprovado no Senado no dia 15 de dezembro de 2015, depois de mobilização da Magistratura. Conforme noticiou a Associação dos Magistrados Brasileiros (AMB), "as principais mudanças se referem à manutenção do juízo prévio de admissibilidade dos recursos especiais ao Superior Tribunal de Justiça e extraordinário ao Supremo Tribunal Federal e ao fim da obrigatoriedade de seguir a ordem cronológica para o julgamento dos processos" 16 .

Em relação a esta alteração vamos destacar três pontos que ajudam a esclarecer melhor a proposta aqui defendida.

Primeiramente há de se destacar a omissão da AMB no que diz respeito ao aumento de poder transferido ao Judiciário com estas alterações, pois, além de manter o juízo prévio de admissibilidade dos recursos especiais ao STJ e extraordinário ao STF, não poderão ser enviados a estas cortes temas por elas já decididos. Não discordamos que a última palavra deva ser proferida pelos tribunais superiores, mas o que se vê com esta mudança é que estes estão sequestrando o âmbito de discussão e de (re)criação do Direito.

Um segundo ponto a se destacar é que esta manobra que proporcionou a mudança do novo CPC antes mesmo deste entrar em vigor foi resultado não de uma tensão entre o Judiciário e o Legislativo, como mostramos acima, mas de um conchavo político entre estes Poderes. E por mais paradoxal que pareça, isto não contradiz o que expusemos até então, mas o confirma. Isto porque se há momentos

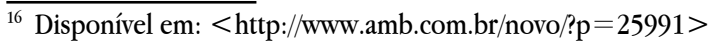


de tensão entre os Poderes, tensão esta que se desenvolve sobre o pano de fundo da interpretação constitucional da atuação de cada um deles, em outros momentos a tensão se dissolve e dá lugar a convergências e acordos.

Não existe, entretanto, qualquer relação de continuidade ou de oposição entre as tensões e as convergências, como se estas fossem a solução daquelas. Se agora o próprio Legislativo concede ao Judiciário tamanho poder, ao contrário do que mostramos antes, não significa que houve um acordo fruto de debate em torno da tensão entre o político e o jurídico, mas uma 'decisão' acerca de assunto específico.

O que queremos mostrar é que não há propriamente um debate, mas decisões que só obedecem a uma lógica do poder, encobertas pelo discurso da interpretação correta da Constituição que nada mais é, na verdade, que um discurso sobre a governabilidade. Isto é, decisões desconexas, ora divergentes ora acordadas, mas que mantêm os Poderes em constante conflito, em que cada um invoca a Constituição ou a necessidade de tomar decisões - governar - aquilo que lhe diz respeito, em nome de toda a nação $0^{17}$.

O que interessa é perceber que a tensão não-se-resolve, isto é, tornar-se o próprio paradigma de governabilidade, em que as decisões são todas justificadas apriorística e isoladamente, ou seja, sem um debate amplo na sociedade, mas em 'defesa da sociedade'. E fica claro isto quando o coordenador da comissão da AMB que acompanhou a discussão sobre o novo código, desembargador Marcos Alaor Diniz Granjeia, diz que "é um código novo, com filosofia nova e é necessário experimentá-lo e aprimorá-lo. Em última instância quem vai dizer o que vale ou como será feito diante da vigência do novo código é a magistratura. É o magistrado que vai dizer como o novo código será aplicado" ${ }^{18}$.

Chegamos, então, ao terceiro ponto que merece destaque. Como já dissemos, não discordamos que o Judiciário profira a última palavra em relação aos conflitos que dirime, mas isto é diferente do que afirmou o desembargador. E se sua fala é sintomática desta tensão-que-não-se-resolve como paradigma de governabilidade, devemos ressaltar também que o intuito não é resolver de uma vez

\footnotetext{
${ }^{17}$ Esta governabilidade a que nos referimos é aquela indicada por Foucault no que diz ser a biopolítica, isto é, um governo que se dirige não mais, somente, aos indivíduos como era a disciplina, mas sobre toda a sociedade. E cada instituição se vale deste discurso de poder para justificar suas ações e decisões. Cf. Foucault, Michel. Em defesa da sociedade: curso no Collège de France (1975-1976). Tradução de Maria Ermantina Galvão. 2. ed. São Paulo: WMF Martins Fontes, 2010.

${ }^{18}$ Disponível em: <http://www.amb.com.br/novo/?p=25991>
} 
por todas a tensão entre o político e o jurídico. Mas, antes, chamar a atenção para o fato de que não estamos pensando-a.

Esta relação entre o direito e a política é fundamental, ela é constitutiva do próprio ser humano, e por isto qualquer discurso que não a pense de modo autêntico estará, de antemão, condenado a uma superficialidade que se mostra cada vez mais trágica para as nossas instituições e a convivência humana. Acreditamos que tanto as respostas ou decisões provenientes do Judiciário como do Legislativo (e também, claro, do Executivo), sejam convergentes ou dissonantes, se mostram carentes de legitimidade porque não provenientes de um âmbito de problematização mais profundo e condizente com os problemas que nos assolam hodiernamente.

Não que as discussões em torno do novo CPC não sejam importantes, mas não podem se situar neste nível superficial, não se pode prescindir de discutir a própria condição de possibilidade do que é o direito, o que é a política e de sua relação em um nível mais fundamental, ontológico até.

Qualquer que seja o discurso, se desconectado destas questões mais elementares a respeito do próprio fenômeno jurídico enquanto constitutivo do ser humano, não passará de engodos argumentativos que não se sustentam e, além do mais, constituem um dos principais perigos para a democracia. Conforme indica Ari Marcelo Solon, o direito (e a política) não pode(m) ser pensado(s) corretamente se não levarmos em consideração o problema de sua legitimidade a partir da noção de soberania. E esta, correlata ao problema da legitimidade do direito, é o que deve ser (constantemente re) problematizado ${ }^{19}$.

Com esse exemplo verificamos a quantas temos andado em nosso país na já mencionada no início deste texto relação entre a teoria e a prática jurídica. Estamos no meio de uma batalha de cegueira epistemológica em que ao mesmo tempo em que a mudança legislativa do Código de Processo Civil aumenta consideravelmente o poder dos juízes, em um contexto absurdo em que o próprio STF dá o exemplo, os próprios magistrados se esforçam para o aprimoramento da concentração de-maispoder, colocando a Constituição de lado, em outras palavras, tomando uma postura inconstiucional, em que a exceção é que dita a regra.

Quando se parte de uma compreensão estática da Constituição, seja ela substancialista ou procedimental, não importa o quanto se privilegie um conteúdo específico ou o modo de se aplicar a Constituição, nunca será possível obter

${ }^{19}$ Cf. SOLON, Ari Marcelo. Teoria da soberania como problema da norma jurídica e da decisão. Porto Alegre: Sergio Antônio Fabris, 1997. 
respostas que possam ser legítimas, pois estas não devem impor aos participantes do jogo social que assumam um ponto de partida ou um ponto de chegada nos quais se possa vislumbrar a unidade, ou seja, o vínculo que sustenta a sociabilidade. Deve-se, ao contrário, explicitar o ponto de partida que assume cada participante para, em seguida, confrontando-o com um ou vários outros que sejam diferentes, possa-se construir conjuntamente novas formas de vida, que leve em consideração todos os pontos de vista envolvidos. Por isso que deve haver uma solução de compromisso entre as partes conflitantes, pois o resultado do conflito não pode ser pré-determinado, não pode se impor aos envolvidos uma resposta que se fie em um referencial exterior a todos, seja ele de que índole for, nem se pode pressupor uma condição de igualdade entre os participantes, o que não é possível pragmaticamente.

Deste modo podemos destacar que por mais evidente que seja a necessidade de se aperfeiçoar de modo geral o Direito, a aposta em um novo CPC, se não acompanhada de transformações mais essenciais, ou seja, no âmbito das instituições, não será suficiente para alcançar os objetivos propostos, nem mesmo para darmos um salto qualitativo no que diz respeito à nossa democracia.

Se hoje enfrentamos graves problemas devido ao ativismo judicial, por exemplo, não é fazendo um novo diploma de processo civil que poder-se-á resolver a questão - ainda mais quando podemos notar que a tendência seja mais de aumentar o grau de protagonismo dos juízes que de contê-lo - posto que podemos afirmar que este problema não poderia ser tolerado já em face de nossa Constituição Federal.

Não desconhecendo os problemas de gestão no que diz respeito ao Judiciário, não podemos, entretanto, endossar as críticas da OAB/SP de que este seria um caminho mais plausível para se resolver os problemas do que a formulação de um novo CPC. Ademais, gostaríamos de deixar claro que investir na gestão teria o mesmo efeito que o novo código no que diz respeito às questões fundamentais, ou seja, não podem proporcionar melhores caminhos de se enfrentar legitimamente os problemas inerentes à judicialização da política decorrente do Estado Democrático de Direito, que não pode ceder ao ativismo judicial nem solapar o devido papel de destaque a ser assumido por uma Corte Constitucional.

A Constituição não pode ser utilizada para bloquear discussões fundamentais nem para sustentar interpretações incorretas, e entre estas estão tanto as que são de cunho solipsistas quanto as que acreditam superar o sujeito apoiando-se em outro referencial legitimador, seja racional ou embasado na historicidade como se daí pudesse decorrer uma decisão desubjetivizada. 
Assumindo este caráter procedimental da Constituição, o qual é capaz de superar o dualismo entre as posturas procedimentalistas e substancialistas, podemos endossar todas as críticas apresentadas ao ativismo judicial baseadas em juristas que assumem esta posição e desempenham papel fundamental para o aperfeiçoamento do Direito, tanto na academia quanto na prática jurisdicional.

Acreditamos que muitas de nossas instituições, envolvidas diretamente na compreensão e aplicação do Direito e, consequentemente, comprometidas com a Constituição e a democracia, precisam de profundas alterações para se colocarem em condições de realmente dar melhores respostas a tantos problemas em nosso país. Falamos especialmente da Academia, da OAB e das carreiras públicas com ingresso mediante concurso. De plano cabe ressaltar o descompasso entre estas instituições, de modo que o ensino jurídico brasileiro se mostra decadente, posto que notamos na Academia grades desatualizadas e defasadas em relação a uma formação humanística, com depreciação das matérias propedêuticas, o que faz do curso de Direito, no Brasil, quase que um curso técnico. Sem falar que este ensino tende cada vez a se render às provas para se inscrever nos quadros da $\mathrm{OAB}$ quanto às provas para ingresso nas carreiras públicas, ambas, de modo geral, distantes de problemas mais profundos como os aqui levantados, ainda caudatárias de processo que seleciona os mais bem preparados para cada prova, especificamente, e não para a função a ser desempenhada.

Reconhecemos que parcela pequena de juristas se volta contra estes processos que fazem o Direito sucumbir à mercadologização, aos manuais simplificados e a incapacidade de afirmar legitimamente sua autonomia, sendo que todos os nomes aqui lembrados estão incluídos entre os que combatem o desmazelo que prepondera em relação ao conhecimento e à prática do Direito. Cremos que estas lutas podem e devem ser feitas por cada um que se comprometa com o constitucionalismo e a democracia, especialmente os que participam das instituições citadas, as quais precisam se voltar urgentemente para as questões levantadas.

\section{REFERÊNCIAS}

BONAVIDES, Paulo. Curso de Direito Constitucional. 25. ed. São Paulo: Malheiros, 2010, p. 105. 
CARNIO, Henrique Garbellini. Para uma crítica da forma jurídica. Revista de Direito Privado, São Paulo, n. 58, abr. 2014.

FOUCAULT, Michel. Em defesa da sociedade: curso no Collège de France (19751976). Tradução de Maria Ermantina Galvão. 2. ed. São Paulo: WMF Martins Fontes, 2010.

GUERRA FILHO, Willis Santiago. Teoria Processual da Constituição. 3. ed. São Paulo: RCS, 2007, p. 51-52.

GUERRA FILHO, Willis Santiago; CARNIO, Henrique Garbellini (Col.). Teoria da Ciência Jurídica. 2. ed. São Paulo: Saraiva, 2009, p. 185-186.

KELSEN, Hans. Dios y estado. In: CORREAS, Óscar (Org.). El outro Kelsen. Tradução de Jean Hennequin. México: Universidad Nacional Autónoma de México, 1989.

MÜLLER, Friedrich. O novo paradigma do direito. São Paulo: Revista dos Tribunais, 2007.

MÜLLER, Friedrich. Teoria Estruturante do Direito. São Paulo: Revista dos Tribunais, 2008, I, p. 80.

REALE, Giovanni. História da filosofia: filosofia pagã antiga. São Paulo: Paulus, 2003, v. 1.

SOLON, Ari Marcelo. Teoria da soberania como problema da norma jurídica e da decisão. Porto Alegre: Sergio Antônio Fabris, 1997.

STRECK, Lenio Luiz. Hermenêutica jurídica e(m) crise: uma exploração hermenêutica da construção do Direito. $8^{\mathrm{a}}$ ed. Porto Alegre: Livraria do Advogado, 2009, p. 38.

Recebido em: 20 de janeiro de 2016 Aceito em: 18 de agosto de 2016 